\section{Besser als Fitness-Sport: Tanzen hält das Hirn im Alter fit}

Tanzen verbessert die kognitive Leistung im Alter offenbar stärker als FitnessSport. Erklärt wird dies mit der multisensorischen Stimulation. Aber auch eine Ernährung mit B-Vitaminen könnte das Gehirn länger fit halten.

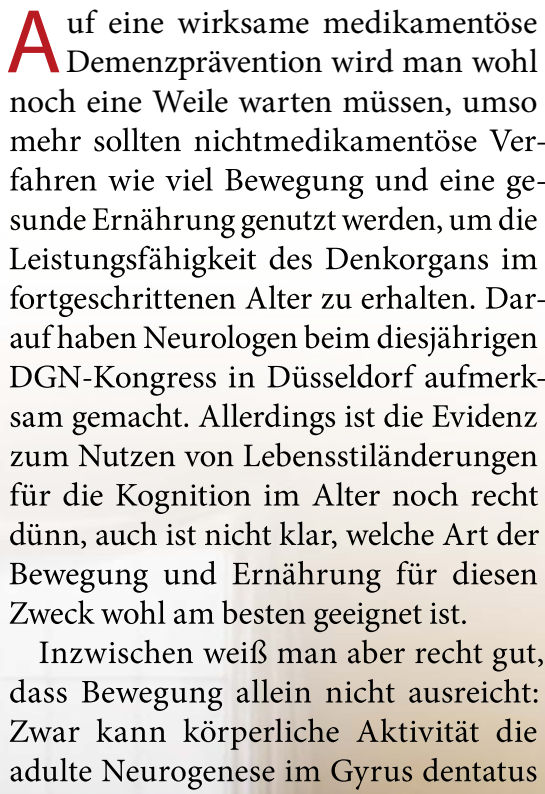

des Hippocampus stimulieren, die neu gebildeten Zellen benötigen jedoch auch eine ausreichende kognitive Stimulation, um zu überleben. In einigen klinischen Studien zeigten sich wenig überraschend besonders dann Effekte auf die kognitive Leistung, wenn körperliches mit geistigem Training kombiniert wurde.

Eine solche multisensorische Stimulation findet auch beim Tanzen statt: Tänzer verarbeiten Musik und versuchen die Bewegungsabläufe mit dem Rhythmus zu synchronisieren, sie absolvieren komplexe dreidimensionale Bewegungen, zugleich kommunizieren sie auf unterschiedlichen Ebenen mit dem Tanzpartner. Tanzen stellt an das Gehirn folglich weitaus größere Anforderungen als ein simples Fitnesstraining mit repetitiven, automatisierten Bewegungen, sagte Professor Notger Müller von der Neurologischen Uniklink in Magdeburg auf dem DGN-Kongress. Sein Team hat aus diesem Grund geprüft, ob ältere Menschen durch Tanzen ihre Hirnleistung stärker verbessern können als mit Fitnesstraining.

Für ihre Studie konnten die Neurologen rund 60 Teilnehmer im Durchschnittsalter von 68 Jahren und mit einem MMST-Wert von im Schnitt 28 Punkten gewinnen. Die Hälfte von ihnen nahm an einem Training mit Fitness- und Kraftübungen (Kontrollgruppe) teil, die übrigen an einem speziellen Tanztraining. Dabei mussten die Teilnehmer immer wieder neue Schritte und Figuren lernen. Das Training dauerte in beiden Gruppen sechs Monate, die Teilnehmer trafen sich dazu zweimal die Woche für eineinhalb Stunden. Ausgewertet wurden anschließend nur Daten von Teilnehmern, die mindestens $70 \%$ der geplanten Trainingsstunden wahrgenommen hatten. Das schafften in jeder Gruppe rund 20 Teilnehmer.

Bei den Kognitionstests zeigten sich die größten Unterschiede sechs Monate später bei der Aufmerksamkeit. In allen drei geprüften Domänen (Wachsamkeit, geteilte Aufmerksamkeit, Flexibilität) waren die Tänzer im Schnitt signifikant besser als vor Trainingsbeginn. Die Sportler hatten sich hingegen nur bei der Wachsamkeit signifikant verbessert. Allerdings gab es keine statistisch belastbaren Unterschiede zwischen den beiden Gruppen. Ein ähnliches Bild ergab sich bei Gleichgewichtstests: Die Tänzer verbesserten sich in zwei von drei untersuchten Domänen, die Sportler nur in einer. Den Gesamtscore für das Gleichgewicht konnten nur die Tänzer signifikant steigern.

Interessant sind auch die gemessenen MRT-Veränderungen: Das Team um Müller fand bei den Tänzern eine Volumenzunahme im Gyrus frontalis medius und Gyrus temporalis, also in Regionen, die mit Aufmerksamkeit und Gedächtnis assoziiert sind, ebenso im cingulären Kortex, der für die Koordination komplexer Bewegungen notwendig ist. Weiterhin nahm auch das Volumen der weißen Substanz im Balken zu.

Die Sportler hingegen steigerten vor allem das Kleinhirnvolumen - möglicherweise ein Ausdruck dafür, dass diese Gruppe vermehrt repetitive Bewegungen trainiert hatte -, aber auch einige Regionen für die visuelle Verarbeitung schienen zu profitieren. Nur bei den Tänzern, nicht jedoch bei den Sportlern kam es im Studienverlauf zu einem signifikanten Anstieg des Neuropeptids Brain-Derived Neurotrophic Factor (BDNF) im Serum. Der Nervenwachstumsfaktor ist unter anderem für die Neurogenese und das Langzeitgedächtnis wichtig.

Aus diesem Grund hat es das Team um Müller überrascht, dass sich bei den Tänzern keine signifikanten Gedächtnisverbesserungen zeigten. Möglicherweise sei die Dauer der Intervention dafür zu kurz gewesen. Die Studie wurde daher um eineinhalb Jahre verlängert, inzwischen ließen sich in der Tat auch hier erste Verbesserungen nachweisen.

(tm)

Minisymposium: Lifestyle-Faktoren bei kognitiver Beeinträchtigung - ein möglicher Ansatz für Interventionsstudien. 88. Kongress der Deutschen Gesellschaft für Neurologie (DGN); Düsseldorf, 23.-26.9.2015 